\title{
Redox Solid Energy Boosters for Flow Batteries: Polyaniline as a Case Study
}

Elena Zanzola, C. R. Dennison, Alberto Battistel, Pekka Peljo, Heron Vrubel, Véronique Amstutz, and Hubert H. Girault*

Laboratoire d'Electrochimie Physique et Analytique

École Polytechnique Fédérale de Lausanne - Valais Wallis

CH-1951 Sion, Switzerland

\author{
Submitted as a Technical Manuscript to \\ Electrochimica Acta - ICEI Special Issue
}

Original submission date: December 29, 2016

Revised submission date: February $27^{\text {th }}, 2017$

Final submission date: March $3^{\text {rd }}, 2017$ 


\begin{abstract}
In this work, the viability of polyaniline as a solid charge storage material in an aqueous redox-mediated flow battery is investigated. Fe(III/II) and V(IV/III) were identified as potential redox mediators to target the emeraldine-pernigraniline and leucoemeraldine-emeraldine redox transitions of the polymer. An indirect chemical cycling method was developed and used to investigate the charging/discharging of the polymer by the selected redox mediators. With $\mathrm{Fe}(\mathrm{III} / \mathrm{II})$ as a redox mediator, respectable specific capacity and cycling stability were demonstrated over 25 cycles. $\mathrm{V}(\mathrm{IV} / \mathrm{III})$ was deemed unsuitable as a redox mediator, due to rather poor kinetics. When added to the electrolyte tanks of a complete flow battery, a conductive composite of polyaniline and carbon black provided a significant improvement in capacity, exhibiting a specific capacity of $64.8 \mathrm{~mA} \mathrm{~h} \mathrm{~g}^{-1}$ at a current density of 38.5 $\mathrm{mA} \mathrm{cm}{ }^{-2}$. This represents a three-fold improvement in volumetric capacity, compared with the electrolyte alone. Moreover, the addition of the polyaniline composite was observed to lower the overpotential at the positive electrode, providing a considerable improvement in voltage efficiency. This work demonstrates the potential of utilizing redox mediators to enable bulk solid-phase charge storage in the tanks of aqueous redox flow batteries.
\end{abstract}




\section{Keywords:}

redox flow battery; redox targeting; redox mediator; solid charge storage materials; polyaniline 


\section{Introduction}

Currently, electric energy demand exceeds $20 \mathrm{TWh} /$ year and it is growing at a rate of about 3\% per year [1]. Growing concerns about energy security and the environment are driving a global shift away from fossil fuels, toward renewable, carbon-neutral energy sources such as wind and solar. However, our reliance on these resources cannot expand beyond $20-50 \%[2,3]$ without simultaneous installation of grid-scale electrical energy storage capacity to help match energy production with energy consumption. Redox flow batteries (RFBs) are a particularly promising technology for large scale installations because their unique design makes them highly scalable and flexible. The energy density of RFBs, however, remains a critical problem, requiring large tanks of electrolyte to achieve rather modest energy storage capacities $[4,5]$.

The maximum energy density of classical RFB systems is determined by the limits of solubility of the active species. In practice, the concentration of active species is limited from 1 to $3 \mathrm{M}$, yielding achievable energy density of approximately 25 to $40 \mathrm{Wh} / \mathrm{L}$ of electrolyte [6-10]. Recently, $\mathrm{Mn}(\mathrm{VII} / \mathrm{VI})$ was proposed as a high energy density positive electrolyte in alkaline media with the solubility of $4 \mathrm{M}$ [5]. To bypass these limitations, in 2013 an innovative approach was proposed by Wang and co-workers, utilizing solid materials as the primary charge storage media [11], which are indirectly charged/discharged via a soluble redox mediator. Unlike hybrid flow batteries, wherein the solid charge storage material resides inside the flow cell and directly accepts/donates electrons from/to the external circuit [12], in a redoxmediated flow battery the charge is carried between the flow cell and the solid charge storage material (stored in the tanks) via a redox mediator Thus, a distinction must be made between the electrode (which serves only to reversibly transfer charge to/from 
the redox mediator, located within the flow cell) and the solid charge storage material (where the bulk charge storage occurs, located inside the tanks).

In the most general form, a soluble redox mediator, $\mathrm{M}$, is reversibly oxidized inside of a flow cell:

$$
\mathrm{M}^{x+}(\mathrm{aq}) \rightarrow \mathrm{M}^{(x+1)+}(\mathrm{aq})+e^{-}
$$

The oxidized mediator is then transported to the storage tanks, where an appropriate solid charge storage material, S, is contained. Upon interacting, the charge is reversibly transferred from the redox mediator to the solid storage material:

$$
\mathrm{M}^{(x+1)+}(\mathrm{aq})+\mathrm{S}^{y+}(\mathrm{s}) \rightarrow \mathrm{M}^{x+}(\mathrm{aq})+S^{(y+1)+}(\mathrm{s})
$$

During this reaction, the redox mediator is again reduced, and thus may be returned to the cell for subsequent charging (Eq 1). In this way, the redox mediator shuttles charge between the flow cell and the solid charge storage material contained in the tanks (Figure 1). This process may continue until the solid storage material is completely saturated with charge. Both of these processes (Eqs 1 and 2) may be reversed in a similar manner, with $\mathrm{S}$ acting as an electron acceptor. Additionally, Eqs 1 and 2 are given for aqueous solutions, but may also occur in organic media.

In their first work on this topic, Wang and co-workers utilized iron phosphate $\left(\mathrm{FePO}_{4}\right)$ in the positive electrolyte storage tank as the solid charge storage material to host intercalation of lithium $\left(\mathrm{Li}^{+}\right)$. Two redox mediators, ferrocene and ferrocenium bromide, were utilized to facilitate oxidation and reduction of the $\mathrm{FePO}_{4}$, respectively. To date, this group has demonstrated this concept (denoted 'redox targeting') using 
$\mathrm{FePO}_{4}[11,13-15]$ and $\mathrm{TiO}_{2}[15,16]$ as solid charge storage materials, and a variety of redox mediators. The same authors estimate that a RFB utilizing this concept could achieve ca. $500 \mathrm{Wh} \mathrm{L}^{-1}$, which is approximately a ten-fold increase in versus energy density of current vanadium RFBs [15].

A redox mediated approach has also been applied to fuel cells, where a polyoxometalate redox mediator is employed on the cathode, and externally regenerated in air [17]. Soluble redox active polymers have also been proposed for flow batteries [18].

A related approach, where excess electricity is converted to $\mathrm{H}_{2}$ and $\mathrm{O}_{2}$ through indirect water electrolysis, has been previously demonstrated by Girault and coworkers $[19,20]$. Similar works using organic and molecular metal oxide redox mediators were also reported previously [21,22]. Wang and co-workers have also demonstrated redox-mediated oxygen evolution/reduction using the same principle [23].

In principle, redox-mediated flow batteries should be readily scalable. Flow batteries already exist at reasonably large scales, as do other flow-assisted electrochemical processes. The engineering of heterogenous flow-through reactors is well established, and is nearly ubiquitous across the chemical industries. Designers of redox-mediated flow batteries would benefit directly from the existing knowledge in these fields. The primary barrier to scale-up is expected to be the availability of the active materials (both the solid charge storage material and the redox mediators) in ton-quantities.

Despite the significant promise of this approach, it has received little attention beyond the studies described here. Moreover, the majority of these studies have focused exclusively on $\mathrm{Li}^{+}$intercalation in organic electrolytes. In the work presented 
here, we apply the redox-mediated flow battery approach to aqueous, acid electrolyte systems, as they are typical of current large scale redox flow batteries.

Polyaniline (PANI) was selected as a solid charge storage material, due to its stability and redox activity in acidic media. PANI is the well-known and characterized polymer of aniline, and it can be readily synthetized, both chemically and electrochemically. The counter anion can influence the rate of the polymerization, the growth mechanism, morphology, and the conductivity of the polymer [24]. Most importantly, PANI exists in three well-defined oxidation states: leucoemeraldine, emeraldine and pernigraniline [25]. Leucoemeraldine and pernigraniline are the fully reduced (all amine groups) and the fully oxidized (all imine groups) forms, respectively, while the intermediate emeraldine form has an amine/imine ratio of ca. 0.5. The presence of two redox transitions (leucoemeraldine-emeraldine, and emeraldine-pernigraniline) presents the opportunity to develop a redox-mediated flow battery utilizing PANI as the solid charge storage material in both tanks. Although an all-PANI redox mediated flow battery would have a relatively low cell voltage (nominally around $0.4-0.6 \mathrm{~V}$ ), it provides a unique platform to investigate the promise of redox-mediated flow batteries.

\section{Experimental}

\subsection{Chemicals}

Hydrochloric acid ( $\mathrm{HCl}, 32 \%$, Carlo Erba) and sulfuric acid $\left(\mathrm{H}_{2} \mathrm{SO}_{4}, 95-97 \%\right)$ were obtained from Carlo Erba and Merck, respectively. Aniline $\left(\mathrm{C}_{6} \mathrm{H}_{7} \mathrm{~N}, 99 \%\right.$ Reagent Plus) and ammonium peroxydisulfate $\left(\left(\mathrm{NH}_{4}\right)_{2} \mathrm{~S}_{2} \mathrm{O}_{8}, 99 \%\right)$ were purchased from Sigma Aldrich. Iron electrolyte solutions were prepared from either ferric (III) sulfate heptahydrate (99\% Sigma Aldrich) or ferrous (II) sulfate heptahydrate (99\% Sigma Aldrich). A Millipore filtration system (Merck Millipore, Billerica, MA) was 
used to generate ultrapure water $(18.2 \mathrm{M} \Omega \mathrm{cm})$ from which all aqueous solutions were prepared. All reagents were employed without further purification. For vanadium electrolyte solutions, a commercial electrolyte was used as-received (Gildemeister Energy Solutions, Germany). The composition of this electrolyte is estimated to be 1.6 $\mathrm{M}$ vanadium, $2 \mathrm{M} \mathrm{H}_{2} \mathrm{SO}_{4}, 50 \mathrm{mM} \mathrm{H}_{3} \mathrm{PO}_{4}$.

\subsection{PANI electrochemical synthesis}

The electrochemical synthesis of PANI was conducted using a PGSTAT 12 potentiostat (Metrohm, CH). Carbon paper (SGL Sigracet 10AA, $36.75 \mathrm{~cm}^{2}$ geometric area) was used as a porous, conductive support for the PANI deposition. A $6 \mathrm{~cm}$ long platinum (Pt) wire was used as the counter electrode, and an $\mathrm{Ag} / \mathrm{AgCl}$ in $3 \mathrm{M} \mathrm{KCl}$ as reference electrode. The electrolyte solution contained $0.2 \mathrm{M}$ aniline in $1 \mathrm{M} \mathrm{HCl}$. The electrochemical deposition was performed under galvanostatic conditions, applying $10 \mathrm{~mA}\left(270 \mu \mathrm{A} \mathrm{cm}^{-2}\right)$ for 7000 seconds. All the experiments were performed at room temperature in air. The resulting PANI supported on carbon paper is denoted herein as PANI/CP.

\subsection{PANI chemical synthesis}

The bulk synthesis of PANI (emeraldine salt) powder was performed at room temperature. $0.77 \mathrm{M}$ aniline was dissolved in $1 \mathrm{M} \mathrm{HCl}$, and subsequently oxidized by adding an equimolar amount of ammonium persulfate. The resulting blue suspension was filtered and washed with milli-Q water until the filtrate became colorless. The collected precipitate was dried under vacuum in a Schlenk line, with gentle heating at $50^{\circ} \mathrm{C}$ to facilitate water evaporation.

A composite material containing both PANI and 25 wt $\%$ carbon black (denoted PANI/CB) was prepared in the same manner, by dispersing the carbon black in the aniline solution prior to oxidation. All subsequent steps were the same. 


\subsection{Conductivity measurements}

Conductivity measurements were performed using a four-point conductivity test fixture with a $1 \mathrm{~mm}$ probe spacing (Jandel Engineering LTD., UK). All samples were several $\mathrm{mm}$ in each dimension. Samples were submerged in solutions of $\mathrm{Fe}$ (II) and $\mathrm{Fe}(\mathrm{III})$ to obtain the emeraldine and pernigraniline forms of the polymer, respectively. The samples were then washed with sulfuric acid solution and dried thoroughly before analysis. Samples were contacted by the measurement head, and cyclic amperometry from $-1 \mathrm{~mA}$ to $1 \mathrm{~mA}$ was applied using a PGSTAT 12 potentiostat. A linear fit was applied to the I-V data to obtain the sample conductance, from which conductivity was calculated by assuming semi-infinite volume.

\subsection{Cyclic voltammetry $(C V)$}

Cyclic voltammetry was performed in $1 \mathrm{M} \mathrm{HCl}$. The working electrode was an $8 \mathrm{~mm}$ diameter disk of PANI/CP, placed together in a plastic holder with a titanium (Ti) current collector. A platinum wire was used as a counter electrode and $\mathrm{Ag} / \mathrm{AgCl}$ in $3 \mathrm{M} \mathrm{KCl}$ as the reference electrode.

\subsection{Direct electrochemical cycling}

PANI was oxidized/reduced potentiostatically at $0.690 / 0.450 \quad \mathrm{~V}$ and $0.260 / 0.020 \mathrm{~V}$ vs $\mathrm{Ag} / \mathrm{AgCl}$ in $1 \mathrm{M} \mathrm{HCl}$ to determine the intrinsic capacity within the potential windows of $\mathrm{Fe}^{2+} / \mathrm{Fe}^{3+}$ and $\mathrm{V}^{3+} / \mathrm{VO}^{2+}$, respectively. The applied potentials were determined by the Nernst equation, assuming a ratio of 99:1 and 1:99 (ox:red) for the couples. Each of the potentiostatic charge/discharge steps were applied for 10 minutes, and a total of 5 charge/discharge cycles were performed for each sample.

\subsection{Indirect chemical cycling}

Chemically-driven oxidation/reduction of PANI/CP was performed using a ROBO Pro (Fischer Techniques Robotics) robotic positioning system, displayed in 
Figure 2, synchronized with an Ivium CompactStat in a two-electrode configuration. The working electrode assembly, shown in Figure 2c, consisted of an 8mm PANI/CP disk immersed in $1 \mathrm{M} \mathrm{HCl}$ and protected by an anion exchange membrane (Fumasep ${ }^{\circledR}$ FAP-375 PP, FuMA-Tech, thickness 70-80 $\mu \mathrm{m}$ ), to prevent the redox mediator from directly oxidizing/reducing the PANI. The counter electrode consisted of either: a coiled Pt wire (for tests involving $\mathrm{Fe}$ ); or an $8 \mathrm{~cm}^{2}$ piece of graphite felt (SGL Sigracet, for tests involving V). The working and counter electrodes were both fixed to the arm of the positioning system. The positioning system moved the electrodes between three beakers containing $0.3 \mathrm{M}$ oxidizing solution (either $\mathrm{Fe}^{3+}$ or $\mathrm{VO}^{2+}$ ), 0.3 $\mathrm{M}$ reducing solution (either $\mathrm{Fe}^{2+}$ or $\mathrm{V}^{3+}$ ), and $1 \mathrm{M} \mathrm{HCl}$ (washing solution), as shown in Figure 2a. First, the electrodes were immersed in the oxidizing solution for 30 minutes, and a potential difference of $0 \mathrm{~V}$ was imposed between the counter and working electrodes. In this configuration, the PANI/CP attempts to reach thermodynamic equilibrium with the solution. Thus, the oxidant was reduced at the counter electrode, while PANI was correspondingly oxidized at the working electrode (simulating indirect charging). The current passing between the two electrodes (named 'chemical current') was measured with the potentiostat. The positioning system then washed the electrodes in $1 \mathrm{M} \mathrm{HCl}$ for 80 seconds, and then immersed the electrodes in the reducing solution. Again, a potential difference of $0 \mathrm{~V}$ was imposed for 30 minutes between the working and counter electrodes, causing the reductant to be oxidized at the counter electrode and PANI to be reduced at the working electrode (simulating indirect discharging). Overall, 25 cycles of chemical charging/discharging were simulated. All experiments were performed in a humidified chamber to minimize evaporation of the various solutions.

\subsection{Flow Cell Tests}


For the flow cell tests, a cell consisting of a $\mathrm{Ti}$ and graphite current collectors (positive and negative half-cells, respectively), carbon felt electrodes (SGL Sigracet), and an anion exchange membrane (Fumasep ${ }^{\circledR}$ FAP-375 PP, FuMA-Tech, $13 \mathrm{~cm}^{2}$ active area) and silicone gaskets were used. The active electrode area was also 13 $\mathrm{cm}^{2}$. The electrolyte solutions were pumped through the cell at a flow rate of $20 \mathrm{~mL}$ $\min ^{-1}\left(0.45 \mathrm{~cm} \mathrm{~s}^{-1}\right.$ mean linear flow velocity) using a multichannel peristaltic pump (Ismatec). A Biologic SP-300 potentiostat was used in a 3-electrode configuration to control the current and positive electrode potential, and the potential of the negative electrode was also actively recorded. Flow cell tests were performed at $200 \mathrm{~mA}$ and $500 \mathrm{~mA}$ (15.4 and $38.5 \mathrm{~mA} \mathrm{~cm}^{-2}$, respectively), and the positive electrode voltage was constrained between 0.250 and $0.890 \mathrm{~V}$ vs. $\mathrm{Ag} / \mathrm{AgCl}$ (in $3 \mathrm{M} \mathrm{KCl}$ ). The reference electrode was placed in the positive electrolyte tank.

For experiments involving PANI or PANI/CB, the electrolyte tanks were configured as a vertical-flow packed bed reactor. Electrolyte returning from the flow cell was injected at the bottom of the tank, below the bed of particles, forcing it to flow upward through the particle bed. A piece of carbon felt was used to prevent the particles from fluidizing and passing through the flow cell. Electrolyte above this filter was pumped back to the flow cell.

\section{Results and Discussion}

\subsection{Electrochemical characterization of PANI, and selection of redox mediators}

The CV in Figure 3 shows both the transition from leucoemeraldine to emeraldine, around $0.150 \mathrm{~V}$, and emeraldine to pernigraniline, around $0.490 \mathrm{~V}$. The oxidation peak corresponding to the transition from emeraldine to pernigraniline is quite broad. The peak anodic/cathodic currents for the two transitions differ, indicating different kinetics for each restructuring of the polymer. The increase of 
current at very positive potentials $(>0.700 \mathrm{~V})$ is attributed to oxidative degradation of the polymer, as reported in other works [26,27]. Additional results to confirm the onset potential of oxidative degradation are presented in the Supporting Information.

Redox mediators were chosen according to their standard potentials to selectively 'target' the two transitions observed in the CV (i.e. leucoemeraldineemeraldine, emeraldine-pernigraniline). On the negative side, the thermodynamic potential window of $\mathrm{V}(\mathrm{IV} / \mathrm{III})\left(\mathrm{E}^{\circ}=0.127 \mathrm{~V} v s \mathrm{Ag} / \mathrm{AgCl}\right)$ overlaps well with the leucoemeraldine-emeraldine transition. On the positive side, the emeraldinepernigraniline transition is ca. $60 \mathrm{mV}$ more negative than the standard potential of $\mathrm{Fe}(\mathrm{III} / \mathrm{II})\left(\mathrm{E}^{\circ}=0.561 \mathrm{~V}\right.$ s $\left.\mathrm{Ag} / \mathrm{AgCl}\right)$, suggesting that $\mathrm{Fe}(\mathrm{III} / \mathrm{II})$ may only facilitate the oxidation of PANI. However, a solution of predominantly Fe(II) (e.g. $99 \%$ of total Fe concentration) can target the reduction of PANI according to the Nernst equation:

$$
E=0.561-0.059 \cdot \log _{10} \frac{0.01}{0.99}=0.443 \mathrm{Vvs} \mathrm{Ag} / \mathrm{AgCl}
$$

Thus, when the Fe solution is sufficiently reduced, it is thermodynamically possible to drive the reduction of PANI. Importantly, Fe(III/II) should also avoid the onset of oxidative degradation (ca. $0.7 \mathrm{~V}$ vs $\mathrm{Ag} / \mathrm{AgCl}$ ). Thus, $\mathrm{V}(\mathrm{IV} / \mathrm{III})$ and $\mathrm{Fe}(\mathrm{III} / \mathrm{II})$ were chosen as the negative and positive redox mediators, respectively, for this work. In the most general sense, the reactions between PANI and the selected redox mediators should proceed as follows:

$$
\begin{aligned}
& {\left[\mathrm{C}_{6} \mathrm{H}_{4} \mathrm{NH}-\mathrm{C}_{6} \mathrm{H}_{4} \mathrm{NH}\right]+\mathrm{V}(\mathrm{IV}) \leftrightarrow\left[\mathrm{C}_{6} \mathrm{H}_{4} \mathrm{NH}-\mathrm{C}_{6} \mathrm{H}_{4} \mathrm{~N}\right]+\mathrm{V}(\mathrm{III})+\mathrm{H}^{+}(4)} \\
& {\left[\mathrm{C}_{6} \mathrm{H}_{4} \mathrm{NH}-\mathrm{C}_{6} \mathrm{H}_{4} \mathrm{~N}\right]+\mathrm{Fe}(\mathrm{III}) \leftrightarrow\left[\mathrm{C}_{6} \mathrm{H}_{4} \mathrm{~N}-\mathrm{C}_{6} \mathrm{H}_{4} \mathrm{~N}\right]+\mathrm{Fe}(I I)+\mathrm{H}^{+}}
\end{aligned}
$$

Once the redox mediators were selected, the supported PANI (PANI/CP) was cycled potentiostatically in the potential window of each redox mediator in order to obtain a first approximation of the practical capacity of the polymer under these 
conditions. The Nernst potentials of the redox mediators at ratios of 99:1 and 1:99 (ox:red) were used to define the potential window for each mediator.

Amperometry for each potential range are presented in Figure 4. In both potential ranges, PANI exhibits atypical Cottrell behavior. For the potential range corresponding to $\mathrm{Fe}(\mathrm{III} / \mathrm{II})$ (Figure 4a), there appear to be two distinct linear regions which approximately intersect around $1.3 \mathrm{~s}^{-1 / 2}$. The exact cause of this behavior is not clear, but it suggests that the system is sequentially controlled by two different transport processes (e.g. diffusion of anions in the bulk electrolyte initially, followed by diffusion of anions within the polymer structure). This behavior is not apparent in the potential window corresponding to V(IV/III) (Figure 4b).

Three PANI/CP samples were tested in each potential range, and each sample was cycled 10 times. The average specific capacity in the potential range from 0.450 $\mathrm{V}$ to $0.690 \mathrm{~V}$ (corresponding to $\mathrm{Fe}\left(\mathrm{III} / \mathrm{II}\right.$ )) was found to be $31.7 \mathrm{~mA} \mathrm{~h} \mathrm{~g}^{-1}$ (normalized to the mass of the polymer), with a standard deviation of $7.2 \mathrm{~mA} \mathrm{~h} \mathrm{~g}^{-1}$. The average specific capacity in the potential range from $0.020 \mathrm{~V}$ to $0.260 \mathrm{~V}$ was marginally lower, $30.6 \mathrm{~mA} \mathrm{~h} \mathrm{~g}^{-1}$, with a standard deviation of $5.2 \mathrm{~mA} \mathrm{~h} \mathrm{~g}^{-1}$. It should be noted that although this measured capacity is significantly lower than the theoretical specific capacity for PANI (ca. $144 \mathrm{~mA} \mathrm{~h} \mathrm{~g}^{-1}$ ) [28], it is a first approximation of the capacity which is accessible with a single redox mediator. Assuming a density of $1.3 \mathrm{~g} \mathrm{ml}^{-1}$ [29], PANI paired with $1 \mathrm{M} \mathrm{Fe(III/II)} \mathrm{can} \mathrm{provide} \mathrm{a} \mathrm{volumetric} \mathrm{capacity} \mathrm{of} 41.2 \mathrm{~mA} \mathrm{~h}$ $\mathrm{ml}^{-1}$, which is an enhancement of ca. $54 \%$.

\section{2 'Indirect' cycling of PANI}

The capacity values obtained in the previous section are representative of the direct reduction/oxidation activity of PANI. However, in the proposed system, PANI would be charged/discharged chemically, via a redox mediator. Thus, the redox 
mediator may impose additional limitations on the achievable capacity. To quantify the available capacity under indirect chemical charging conditions, PANI/CP was cycled in oxidizing and reducing solutions using a robotic positioning system, as described in the Experimental Methods section.

First, PANI/CP was cycled between solutions of $\mathrm{Fe}^{3+}$ and $\mathrm{Fe}^{2+}$. The specific capacity for each cycle is presented in Figure 5. The capacity was stable over 25 cycles, with an average value of $45.7 \mathrm{~mA} \mathrm{~h} \mathrm{~g}^{-1}$. This average capacity is higher than the value obtained by direct electrochemical cycling of the polymer, most likely due to the longer charge/discharge time. The coulombic efficiency was also very stable throughout the experiment. The Cottrell plot shown in the inset of Figure 5 is similar to that obtained by direct electrochemical cycling, with two distinct linear regions. This suggests that the observed current is limited by the transport processes associated with PANI, rather than diffusion of the redox mediator.

PANI/CP was also chemically cycled using solutions of $\mathrm{V}^{3+}$ and $\mathrm{VO}^{2+}$ as the reductant and oxidant, respectively. Despite the respectable specific capacity obtained by direct electrochemical cycling in this potential window, indirect chemical cycling using V(IV/III) consistently resulted in very low specific capacity values. This is largely attributed to the relatively poor kinetics of the V(IV/III) couple. Indeed, in many prior works, oxidation and reduction peaks attributable to $\mathrm{V}(\mathrm{IV} / \mathrm{III})$ cannot be readily identified, suggesting that $\mathrm{VO}^{2+}$ is more readily reduced directly to $\mathrm{V}^{2+}$, and similarly $\mathrm{V}^{3+}$ is more readily oxidized to $\mathrm{VO}_{2}{ }^{+}$[30]. As a result of the kinetic limitations of the redox mediator, PANI/CP could not be significantly charged/discharged. Increasing the surface area of the counter electrode to provide more reaction sites for the redox mediator yielded only modest gains, with an average specific capacity of $5.6 \mathrm{~mA} \mathrm{~h} \mathrm{~g}^{-1}$ over 25 cycles (see Supplemental Information for 
more details). Although disappointing, this result illustrates the complimentary roles of the redox mediator and the solid charge storage material, and emphasizes the need to screen them in tandem.

\section{3 Characterization of a Complete RFB}

As a full proof-of-concept, PANI was added to the tanks of a complete Fe/V redox flow battery. However, before adding PANI the baseline capacity of the electrolytes $(40 \mathrm{~mL}, 1 \mathrm{M} \mathrm{Fe} / \mathrm{V}$ on each side) was measured at a current of $200 \mathrm{~mA}$ $\left(15.4 \mathrm{~mA} \mathrm{~cm}^{-2}\right)$ and found to be $962.7 \mathrm{~mA} \mathrm{~h}$, or about $90 \%$ of the theoretical capacity. At $500 \mathrm{~mA}\left(38.5 \mathrm{~mA} \mathrm{~cm}^{-2}\right)$ the capacity was $756 \mathrm{~mA} \mathrm{~h}$ (ca. $70 \%$ of the nominal capacity).

Subsequently, ca. $6.8 \mathrm{~g}$ of PANI was added to each electrolyte tank. Based on the specific capacity values measured in Section 3.1, this amount of PANI was expected to increase the overall capacity of the battery by ca. $20 \%$. However, upon cycling the cell at $200 \mathrm{~mA}\left(15.4 \mathrm{~mA} \mathrm{~cm}^{-2}\right)$, the capacity was found to be $840 \mathrm{~mA} \mathrm{~h}$, an overall reduction of $12.8 \%$ versus the baseline case. This reduction in overall capacity was hypothesized to be due to passivation of the exterior surface of the PANI particles.

One theory was that this passivation was the result of changes in It has been established in literature that only the intermediate emeraldine state of PANI is a good electronic conductor. The fully oxidized and reduced forms (pernigraniline and leucoemeraldine, respectively) exhibit several orders of magnitude decrease in electronic conductivity versus the emeraldine form [31-34]. Thus, charge transfer to the interior of the particle would become increasingly difficult as the exterior surface is converted. After the exterior of the particle has passivated, oxidation/reduction of the interior of the PANI particle would only possible by diffusion of the redox 
mediator within the pore structure of the particle, imposing a significant ratelimitation.

It is also possible that the kinetics of the redox mediators change significantly with the oxidation state of the PANI. In such a case, the exterior surface of the particle is essentially kinetically-passivated. Again, after passivation further oxidation/reduction of the interior of the particle would only be possible by diffusion of the redox mediator into the PANI particle.

The exact mode of passivation is not clear from the available data. Indeed, the same passivation behavior may have also affected the previous measurements involving PANI/CP, whereby the polymer in close contact with the conductive carbon fibers may be oxidized/reduced, and thus become insulating, preventing the remaining polymer further from the fibers from being electrically addressable. This insulating effect would lead to a lower measured capacity. An additional capacity loss in the flow battery may be due to a portion of the redox mediator ions entering the pore structure and leaving the circulating electrolyte, thus becoming inaccessible during cycling.

To address these limitations, a conductive composite of PANI and carbon black was prepared. The carbon black was intended to ensure that the interior of the PANI particle was electronically addressable, and to provide alternative reaction sites for the redox mediator at the surface of the particle. In this way, the carbon black network should enable the redox mediator to react immediately at the surface rather than needing to diffuse into the solid particle before reacting. A comparison of the electronic conductivity of PANI and PANI/CB is given in Table 1. Incorporating carbon black into the PANI structure increased the electronic conductivity more than four-fold. 
Satisfied with this improvement in conductivity, $9.87 \mathrm{~g}$ of PANI/CB (corresponding to $7.4 \mathrm{~g}$ PANI) was added to each electrolyte tank of the battery. The battery was again cycled at $200 \mathrm{~mA}\left(15.4 \mathrm{~mA} \mathrm{~cm}^{-2}\right)$, and a capacity of $1433.0 \mathrm{~mA} \mathrm{~h}$ was observed. This capacity represents an improvement of $49 \%$ over the baseline capacity at the same current, and is equivalent to a specific capacity of $47.7 \mathrm{~mA} \mathrm{~h} \mathrm{~g}^{-1}$ for PANI/CB (63.6 mA h g ${ }^{-1}$ normalized to the mass of PANI alone). This specific capacity exceeds the values measured by direct electrochemical cycling and indirect chemical cycling of PANI, despite the numerous additional loss mechanisms that are present in a redox flow cell. This suggest that the capacity values obtained for PANI/CP may have also been limited by the formation of an insulating layer of PANI adjacent to the carbon fibers, and are thus an underprediction of the performance of the polymer.

When the cell was cycled at $500 \mathrm{~mA}\left(38.5 \mathrm{~mA} \mathrm{~cm}^{-2}\right)$, the addition of PANI/CB provided a total capacity of $1235.8 \mathrm{~mA} \mathrm{~h}$, an improvement of ca. $64 \%$ over the baseline cell at the same current. At this current, PANI/CB provides a specific capacity of $48.6 \mathrm{~mA} \mathrm{~h} \mathrm{~g}^{-1}$ ( $64.8 \mathrm{~mA} \mathrm{~h} \mathrm{~g}^{-1}$ considering only the mass of the polymer), which is very similar to the capacity at $200 \mathrm{~mA}\left(15.4 \mathrm{~mA} \mathrm{~cm}^{-2}\right)$. This suggests that PANI/CB provides good rate-stability in this redox-mediated configuration, allowing the cell to be cycled at relatively high power. The surface area of the PANI in the tank is presumed to be much larger than the surface area of the electrode in the cell. As a result, the local current density at the surface of the PANI is much lower than the current density in the flow cell, which allows the PANI to tolerate higher charging/discharging rates without a significant loss of capacity.

Importantly, the equivalent volumetric capacity of PANI/CB (assuming a density of $\left.1.3 \mathrm{~g} \mathrm{ml}^{-1}\right)$ is ca. $84.2 \mathrm{~mA} \mathrm{~h} \mathrm{~mL}^{-1}$ at $500 \mathrm{~mA}\left(38.5 \mathrm{~mA} \mathrm{~cm}^{-2}\right)$, which is a 
three-fold increase versus the volumetric capacity of electrolyte alone $(26.8 \mathrm{~mA} \mathrm{~h}$ $\mathrm{mL}^{-1}$ ). This enhancement was obtained using a single redox mediator, although in principle it is possible to use two or more redox mediators to broaden the chemical potential window applied to the solid storage material, which is expected to provide further improvements in capacity. This is a clear example of the potential of this approach to enhance the energy density of redox flow batteries.

The potential measured at the positive electrode (i.e. Fe(III/II)) is shown in Figure 6. At both applied current values, the average potential at the positive electrode is significantly decreased during charging, and increased during discharging. Incorporating PANI/CB in the electrolyte tank essentially 'buffers' the state-of-charge of the electrolyte entering the flow cell for a wide range of capacity, thus lowering/raising the average potential required to sustain the current during charging/discharging, respectively. At $200 \mathrm{~mA}\left(15.4 \mathrm{~mA} \mathrm{~cm}^{-2}\right)$, the average charging voltage is decreased by $66 \mathrm{mV}$ versus the baseline, and the average discharging voltage was increased by $51 \mathrm{mV}$. Similarly, at $500 \mathrm{~mA}\left(38.5 \mathrm{~mA} \mathrm{~cm}{ }^{-2}\right)$, the average charging voltage was decreased by $141 \mathrm{mV}$, while the average discharging voltage was increased by $99 \mathrm{mV}$. These significant reductions in overpotential can significantly increase the voltage and energy efficiency of a complete battery system, while simultaneously enabling higher power operation.

As expected from the indirect chemical cycling measurements discussed in Section 3.2, the negative (i.e. $\mathrm{V}(\mathrm{IV} / \mathrm{III})$ ) electrode did not perform as well as the positive electrode. Due to the poor kinetics of the redox mediator, large overpotentials were required to cycle this half-cell at the currents enforced in this work, resulting in some hydrogen evolution during reduction at larger currents. Some buffering effect due to the addition of PANI/CP was still observed, particularly during oxidation, but 
overall the redox mediator was deemed unsuitable for present application. Complete data is provided in the Supporting Information.

A preliminary assessment of the cycling stability of PANI/CB was also performed at $200 \mathrm{~mA}\left(15.4 \mathrm{~mA} \mathrm{~cm}^{-2}\right)$ to determine if any degradation of the material was occurring. It should be noted that these stability measurements were performed after the PANI/CB had been exposed to the redox mediator solutions for nearly two months. As seen in Figure 7, a slight decrease in capacity (ca. 200 mAh, or $12 \%$ of the initial capacity) was observed after 10 cycles, suggesting some degradation of the active material. Interestingly, however, all of the measured capacity values are larger than previous measurements. This may be the result of improved percolation of the PANI/CB by the redox mediator solutions (due to the long term exposure of the PANI/CB to the electrolyte). Considered as a whole, the data suggests the some degradation of PANI/CB is likely to occur at very high states-of-charge. However, in practical systems this effect can be mitigated by limiting the degree of oxidation of the positive electrolyte.

\section{Conclusions}

In this work, the viability of PANI as a solid charge storage material in an aqueous redox-mediated flow battery is investigated. We identified $\mathrm{Fe}(\mathrm{III} / \mathrm{II})$ and $\mathrm{V}(\mathrm{IV} / \mathrm{III})$ as potential redox mediators to target the emeraldine-pernigraniline and leucoemeraldine-emeraldine redox transitions of the polymer, based on the close alignment of their standard potentials with the desired redox transitions. An indirect chemical cycling method was developed and used to investigate the charging/discharging of the polymer by the selected redox mediators. With $\mathrm{Fe}(\mathrm{III} / \mathrm{II})$ as a redox mediator, respectable specific capacity and cycling stability were demonstrated. Cottrell analysis suggested two competing transport modes governing 
the system behavior. Indirect chemical cycling revealed that V(IV/III) is rather unsuitable as a redox mediator in this application, due to it's poor kinetics.

PANI was also chemically cycled in a complete redox flow battery. Interestingly, the cell containing raw PANI in the tanks exhibited a lower capacity than the baseline case. This was attributed to changes in the electronic conductivity of PANI during oxidation/reduction. To mitigate this issue, a composite of PANI and carbon black was prepared and observed to exhibit significantly improved electronic conductivity. When PANI/CB was added to the tanks of the flow battery, the capacity was significantly enhanced. The PANI/CB exhibited a specific capacity of $64.8 \mathrm{~mA} \mathrm{~h}$ $\mathrm{g}^{-1}$ at a current density of $38.5 \mathrm{~mA} \mathrm{~cm}^{-2}$. This represents a 3-fold improvement in volumetric capacity, when compared to the electrolyte alone. Moreover, the addition of the polyaniline composite is believed to 'buffer' the state-of-charge of the electrolyte entering the flow cell, lowering the overpotential required to sustain the desired current. As a result, the voltage and energy efficiency of the battery are improved, and higher power operation is possible. This work demonstrates that solid charge storage materials can increase the energy capacity of aqueous redox flow batteries, while simultaneously enhancing the efficiency and performance of the battery as well.

\section{Acknowledgements}

The authors acknowledge financial support from EOS Holding SA. This work was performed within the Swiss Competence Center for Energy Research (SCCER) Heat and Energy Storage (HaE) framework. Pekka Peljo, would like to thank the Swiss Science Foundation for an Ambizione grant. 


\section{References}

[1] P. Alotto, M. Guarnieri, F. Moro, Redox flow batteries for the storage of renewable energy: A review, Renew. Sustain. Energy Rev. 29 (2014) 325-335.

[2] I. Stadler, Power grid balancing of energy systems with high renewable energy penetration by demand response, Util. Policy. 16 (2008) 90-98.

[3] D. Weisser, R.S. Garcia, Instantaneous wind energy penetration in isolated electricity grids: concepts and review, Renew. Energy. 30 (2005) 1299-1308.

[4] C.R. Dennison, H. Vrubel, V. Amstutz, P. Peljoa, K.E. Toghill, H.H. Girault, Redox Flow Batteries, Hydrogen and Distributed Storage, Chim. Int. J. Chem. 69 (2015) 753-758.

[5] A.N. Colli, P. Peljo, H.H. Girault, High energy density $\mathrm{MnO}$ 4-/MnO $42-$ redox couple for alkaline redox flow batteries, Chem. Commun. 52 (2016) $14039-14042$.

[6] T. Nguyen, R.F. Savinell, Flow batteries, Electrochem. Soc. Interface. 19 (2010) 54

[7] A.Z. Weber, M.M. Mench, J.P. Meyers, P.N. Ross, J.T. Gostick, Q. Liu, Redox flow batteries: a review, J. Appl. Electrochem. 41 (2011) 1137-1164.

[8] M. Skyllas-Kazacos, M.H. Chakrabarti, S.A. Hajimolana, F.S. Mjalli, M. Saleem, Progress in flow battery research and development, J. Electrochem. Soc. 158 (2011) R55-R79.

[9] G. Kear, A.A. Shah, F.C. Walsh, Development of the all-vanadium redox flow battery for energy storage: a review of technological, financial and policy aspects, Int. J. Energy Res. 36 (2012) 1105-1120.

[10] A. Parasuraman, T.M. Lim, C. Menictas, M. Skyllas-Kazacos, Review of 
material research and development for vanadium redox flow battery applications, Electrochim. Acta. 101 (2013) 27-40.

[11] Q. Huang, H. Li, M. Grätzel, Q. Wang, Reversible chemical delithiation/lithiation of LiFePO 4: towards a redox flow lithium-ion battery, Phys. Chem. Chem. Phys. 15 (2013) 1793-1797.

[12] P. Leung, X. Li, C.P. De León, L. Berlouis, C.T.J. Low, F.C. Walsh, Progress in redox flow batteries, remaining challenges and their applications in energy storage, Rsc Adv. 2 (2012) 10125-10156.

[13] Q. Huang, J. Yang, C.B. Ng, C. Jia, Q. Wang, A redox flow lithium battery based on the redox targeting reactions between LiFePO 4 and iodide, Energy Environ. Sci. 9 (2016) 917-921.

[14] J.R. Jennings, Q. Huang, Q. Wang, Kinetics of Li x FePO4 Lithiation/Delithiation by Ferrocene-Based Redox Mediators: An Electrochemical Approach, J. Phys. Chem. C. 119 (2015) 17522-17528.

[15] C. Jia, F. Pan, Y.G. Zhu, Q. Huang, L. Lu, Q. Wang, High-energy density nonaqueous all redox flow lithium battery enabled with a polymeric membrane, Sci. Adv. 1 (2015) e1500886.

[16] F. Pan, J. Yang, Q. Huang, X. Wang, H. Huang, Q. Wang, Redox Targeting of Anatase TiO2 for Redox Flow Lithium-Ion Batteries, Adv. Energy Mater. 4 (2014).

[17] R. Singh, A.A. Shah, A. Potter, B. Clarkson, A. Creeth, C. Downs, F.C. Walsh, Performance and analysis of a novel polymer electrolyte membrane fuel cell using a solution based redox mediator, J. Power Sources. 201 (2012) 159-163.

[18] M. Burgess, J.S. Moore, J. Rodríguez-López, Redox Active Polymers as 
Soluble Nanomaterials for Energy Storage, Acc. Chem. Res. 49 (2016) 26492657.

[19] P. Peljo, H. Vrubel, V. Amstutz, J. Pandard, J. Morgado, A. Santasalo-Aarnio, D. Lloyd, F. Gumy, C.R. Dennison, K.E. Toghill, All-vanadium dual circuit redox flow battery for renewable hydrogen generation and desulfurisation, Green Chem. 18 (2016) 1785-1797.

[20] V. Amstutz, K.E. Toghill, F. Powlesland, H. Vrubel, C. Comninellis, X. Hu, H.H. Girault, Renewable hydrogen generation from a dual-circuit redox flow battery, Energy Environ. Sci. 7 (2014) 2350-2358.

[21] B. Rausch, M.D. Symes, L. Cronin, A bio-inspired, small molecule electroncoupled-proton buffer for decoupling the half-reactions of electrolytic water splitting, J. Am. Chem. Soc. 135 (2013) 13656-13659.

[22] B. Rausch, M.D. Symes, G. Chisholm, L. Cronin, Decoupled catalytic hydrogen evolution from a molecular metal oxide redox mediator in water splitting, Science (80-. ). 345 (2014) 1326-1330.

[23] Y.G. Zhu, X. Wang, C. Jia, J. Yang, Q. Wang, Redox-Mediated ORR and OER Reactions: Redox Flow Lithium Oxygen Batteries Enabled with a Pair of Soluble Redox Catalysts, ACS Catal. 6 (2016) 6191-6197.

[24] M.S. Freund, B.A. Deore, Self-doped conducting polymers, John Wiley \& Sons, 2007.

[25] J.-C. Chiang, A.G. MacDiarmid, "Polyaniline": protonic acid doping of the emeraldine form to the metallic regime, Synth. Met. 13 (1986) 193-205.

[26] A. Thyssen, A. Borgerding, J. W Schultze, Formation and electronic conductivity of polyaniline, in: Makromol. Chemie. Macromol. Symp., Wiley Online Library, 1987: pp. 143-157. 
[27] Y. Wei, G.W. Jang, C.C. Chan, K.F. Hsueh, R. Hariharan, S.A. Patel, C.K. Whitecar, Polymerization of aniline and alkyl ring-substituted anilines in the presence of aromatic additives, J. Phys. Chem. 94 (1990) 7716-7721.

[28] R. Liang, H. Cao, D. Qian, J. Zhang, M. Qu, Designed synthesis of SnO 2polyaniline-reduced graphene oxide nanocomposites as an anode material for lithium-ion batteries, J. Mater. Chem. 21 (2011) 17654-17657.

[29] H.J. Choi, M.S. Cho, K. To, Electrorheological and dielectric characteristics of semiconductive polyaniline-silicone oil suspensions, Phys. A Stat. Mech. Its Appl. 254 (1998) 272-279.

[30] M. Rychcik, M. Skyllas-Kazacos, Evaluation of electrode materials for vanadium redox cell, J. Power Sources. 19 (1987) 45-54.

[31] W.W. Focke, G.E. Wnek, Y. Wei, Influence of oxidation state, pH, and counterion on the conductivity of polyaniline, J. Phys. Chem. 91 (1987) 58135818.

[32] M. Angelopoulos, A. Ray, A.G. Macdiarmid, A.J. Epstein, Polyaniline: processability from aqueous solutions and effect of water vapor on conductivity, Synth. Met. 21 (1987) 21-30.

[33] P.M. McManus, S.C. Yang, R.J. Cushman, Electrochemical doping of polyaniline: effects on conductivity and optical spectra, J. Chem. Soc. Chem. Commun. (1985) 1556-1557.

[34] A.G. MacDiarmid, A.J. Epstein, Polyanilines: a novel class of conducting polymers, Faraday Discuss. Chem. Soc. 88 (1989) 317-332. 


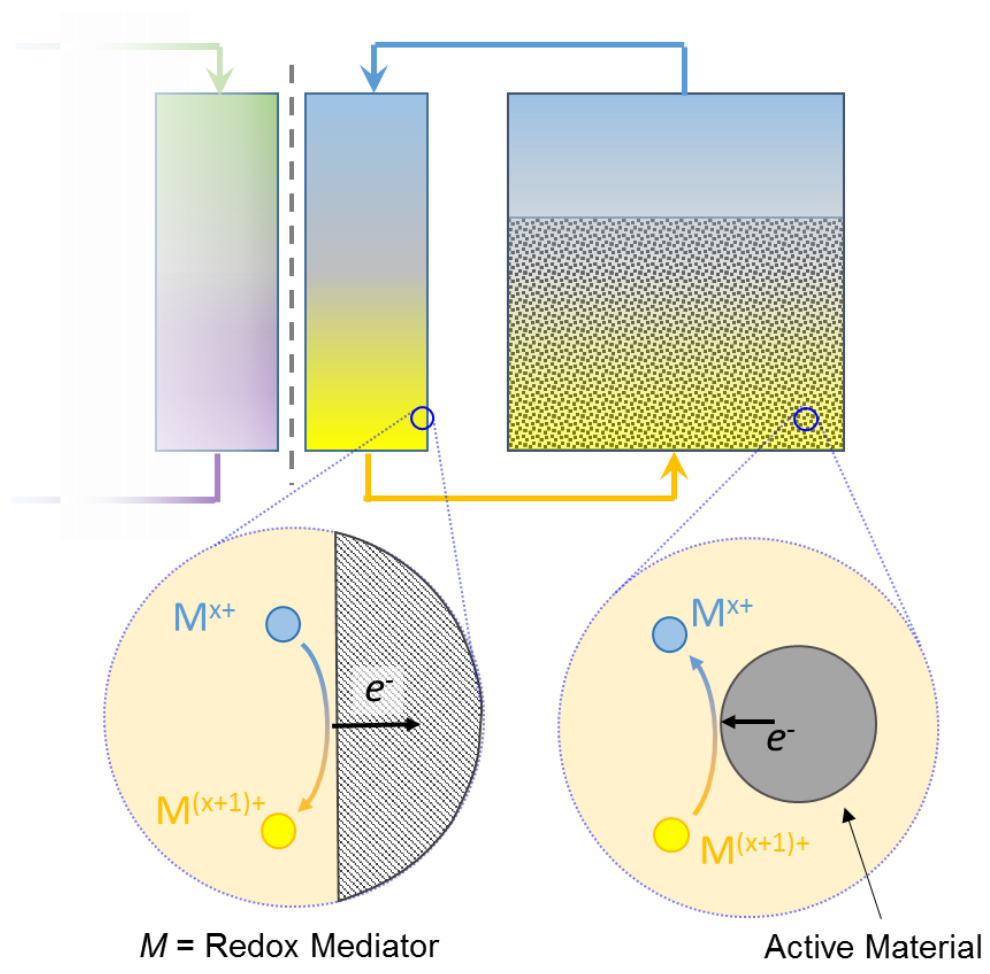

Figure 1. General schematic depicting the operation of one half-cell of a redox-mediated flow battery. 
a)

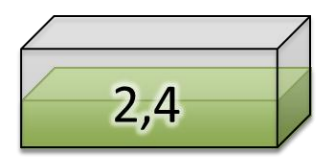

Washing
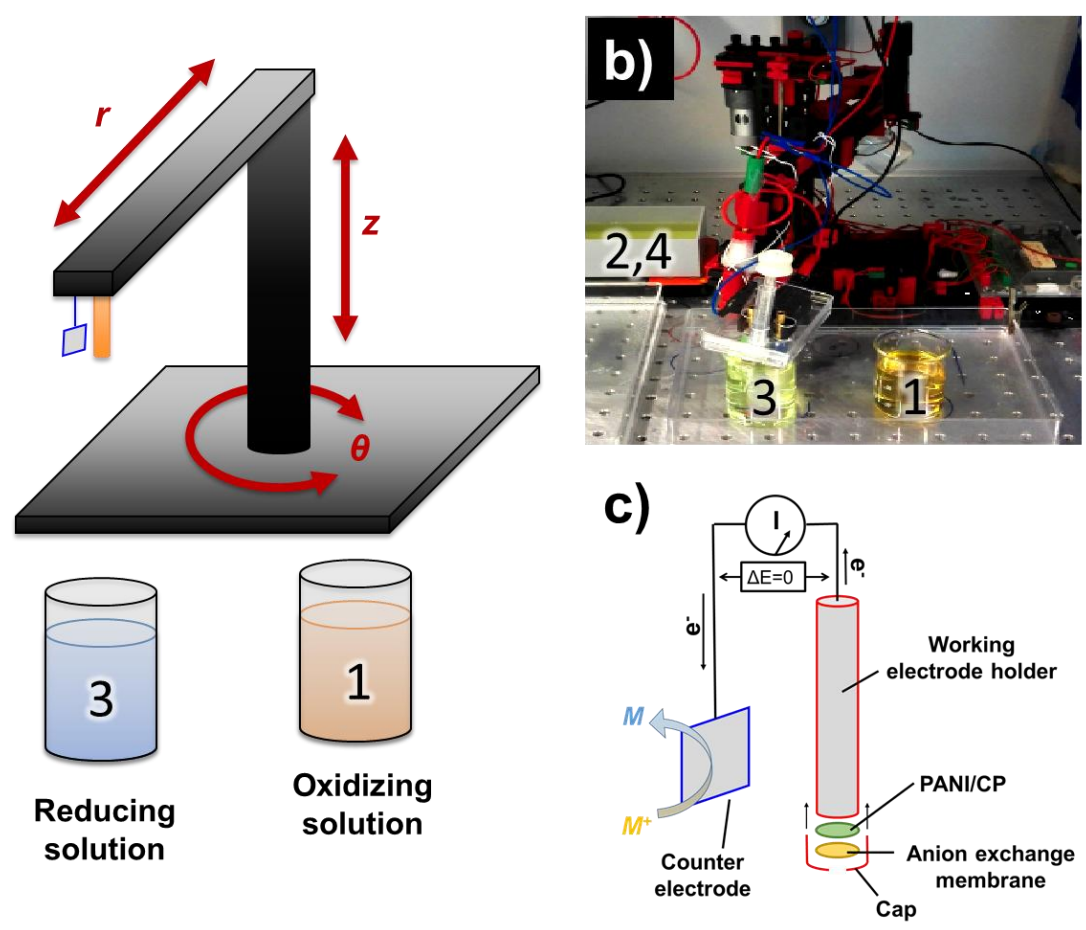

Figure 2. a) Schematic and b) photograph of the experimental setup used to simulate indirect cycling of

PANI. A computer controlled positioning system was used to alternately submerge electrodes into beakers containing a solution of the oxidizing redox mediator (either $\mathrm{Fe}^{3+}$ or $\mathrm{V}^{4+}$, position 1) or a solution of the reducing redox mediator (either $\mathrm{Fe}^{2+}$ or $\mathrm{V}^{3+}$, position 3), with washing steps in between (position 2,4). During each cycle, the potential difference between the two electrodes was fixed to $0 \mathrm{~V}$, and the current was measured (c). 


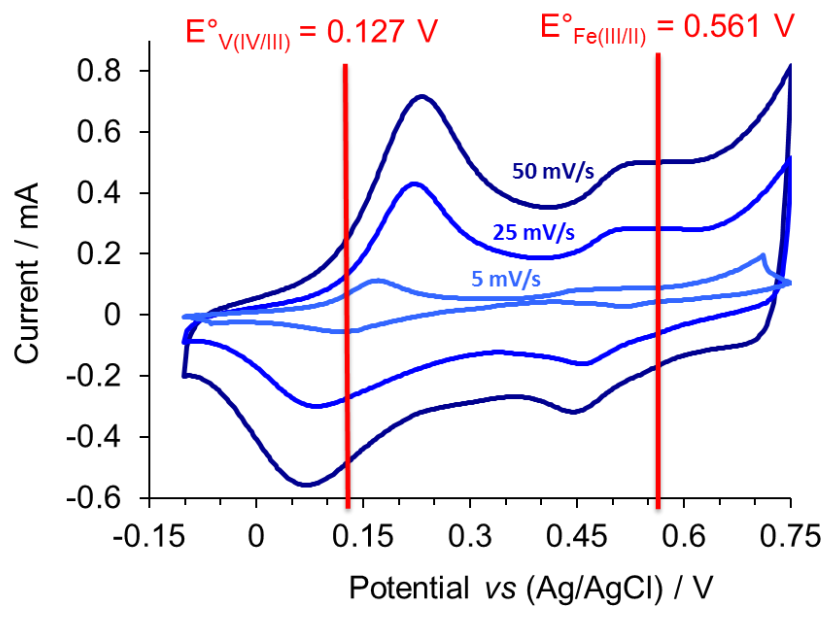

Figure 3. Cyclic voltammetry of PANI/CP performed in $1 \mathrm{M} \mathrm{HCl}$. The standard reduction potentials for the redox mediators $\mathrm{V}$ (IV/III) and $\mathrm{Fe}$ (III/II) are also indicated. 

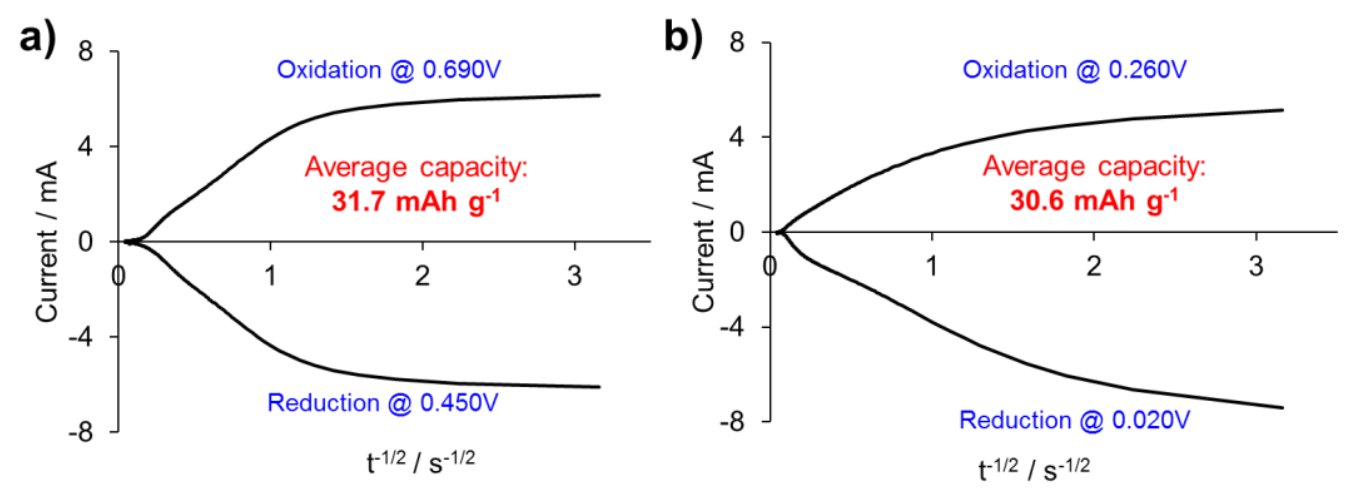

Figure 4. Cottrell plots representing the potentiostatic cycling of PANI in $1 \mathrm{M} \mathrm{HCl}$, in the potential range corresponding to a) $\mathrm{Fe}(\mathrm{III} / \mathrm{II})$ and b) $\mathrm{V}$ (IV/III). 


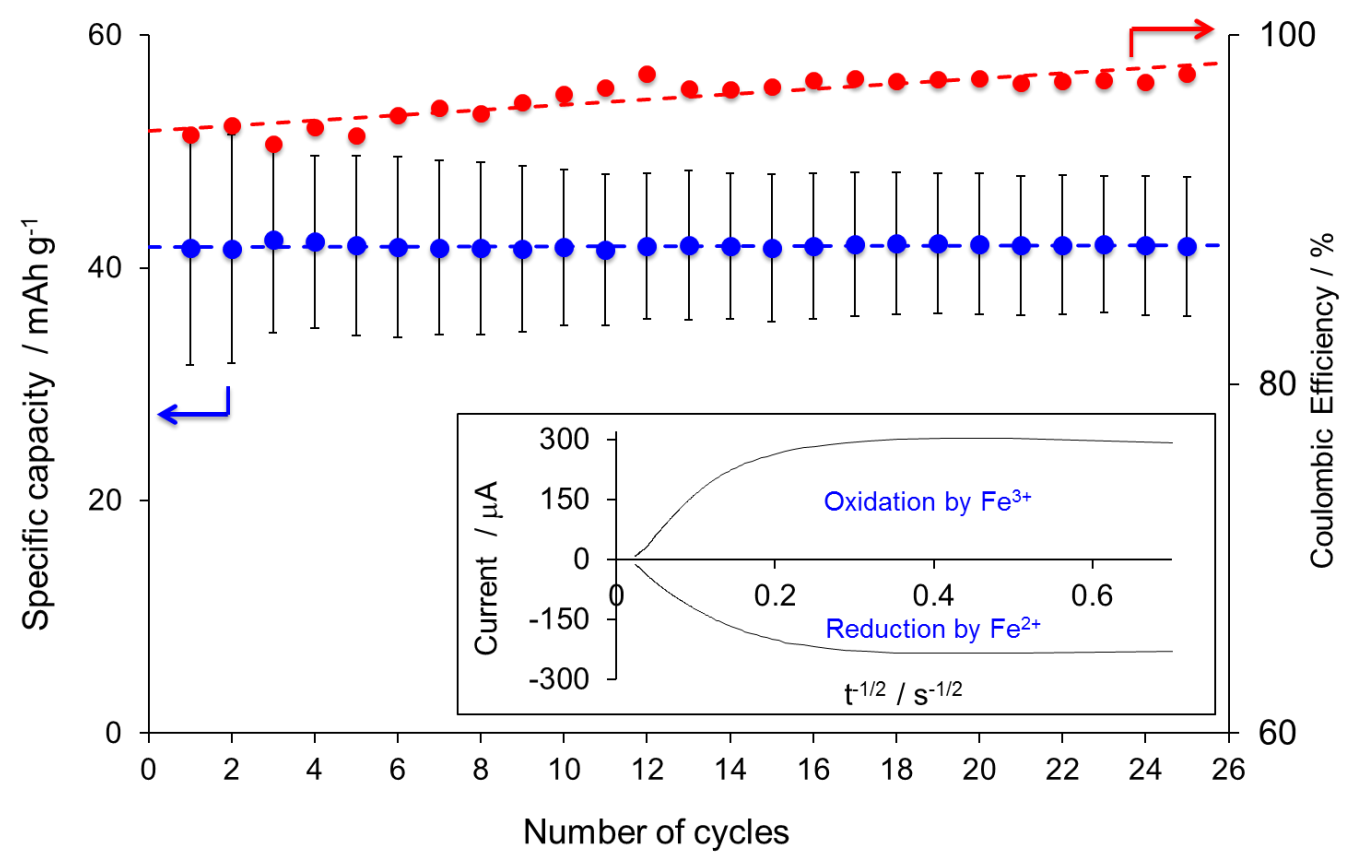

Figure 5. Specific capacity and coulombic efficiency obtained by indirect chemical cycling of PANI/CP in 0.3 $\mathrm{M}$ solutions of $\mathrm{Fe}^{3+}$ and $\mathrm{Fe}^{2+}$. The error bars represent the standard deviation for each cycle among the 3 samples. The inset depicts a Cottrell plot for a typical cycle. 
a)

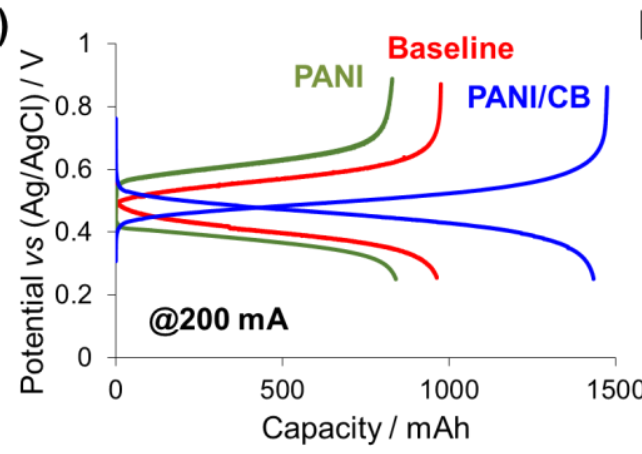

b)

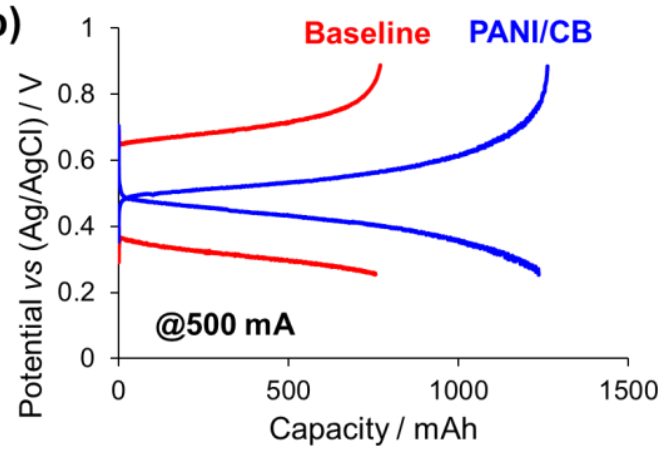

Figure 6. Potential of the positive (Fe(III/II) electrode of a redox flow battery cycling at a) $200 \mathrm{~mA}$ and b) $500 \mathrm{~mA}$ with PANI and PANI/CB added to the electrolyte tanks. The 'baseline' corresponds to cycling of only the electrolyte. Note: the battery containing PANI was not cycled at $500 \mathrm{~mA}$, due to it's poor performance at $200 \mathrm{~mA}$. 


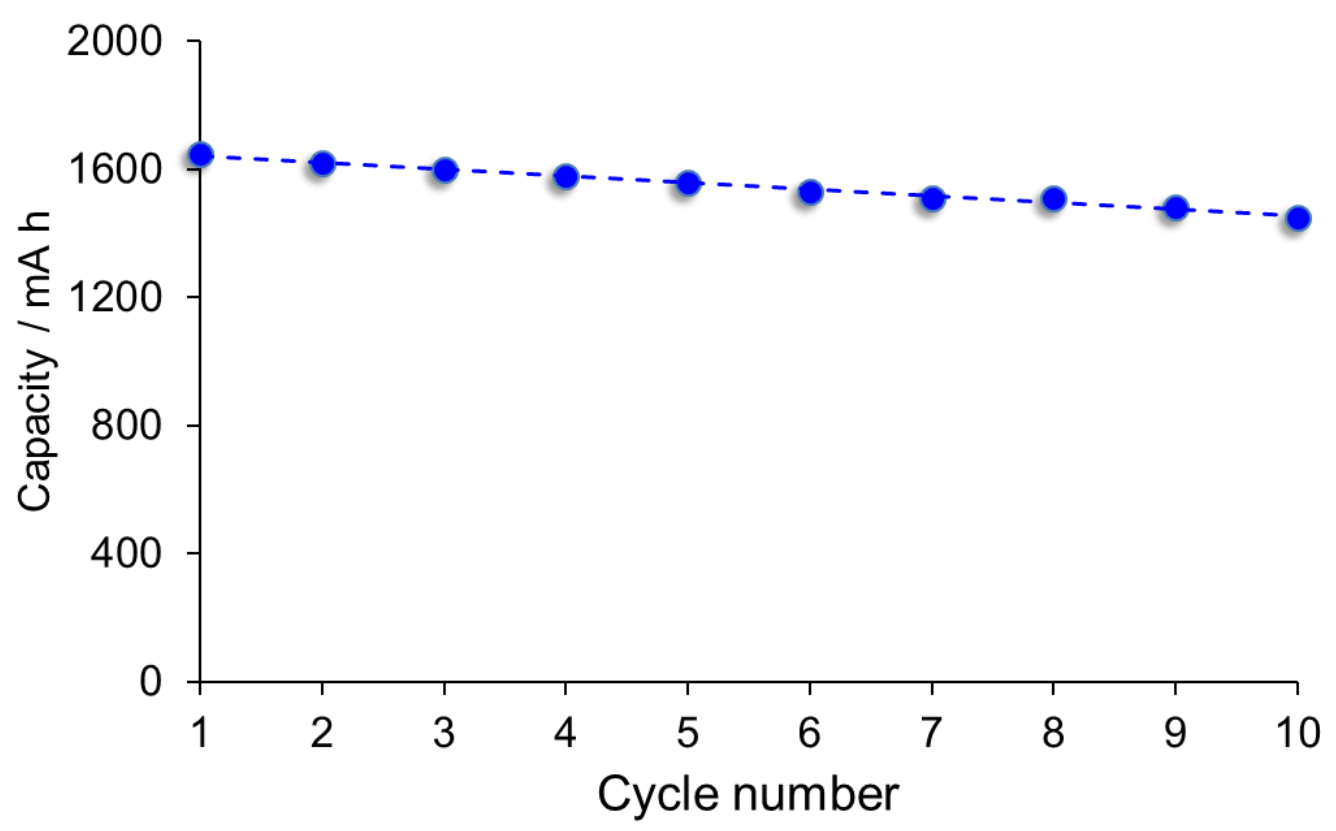

Figure 7. Cycling stability data for PANI/CB at $200 \mathrm{~mA}(15.4 \mathrm{~mA} \mathrm{~cm})$. A slight decrease in capacity is observed. 
Table 1. Summary of dry conductivity values for PANI and PANI/CB.

\begin{tabular}{ccc}
\hline & Emeraldine & Pernigraniline \\
\hline PANI & $1.55 \pm 0.03 \mathrm{~S} \mathrm{~cm}^{-1}$ & $1.30 \pm 0.16 \mathrm{~S} \mathrm{~cm}^{-1}$ \\
PANI/CB & $6.22 \pm 0.86 \mathrm{~S} \mathrm{~cm}^{-1}$ & $6.14 \pm 0.65 \mathrm{~S} \mathrm{~cm}^{-1}$ \\
\hline
\end{tabular}

